\title{
Human and animal Campylobacteriosis in Tanzania: A review
}

\author{
ERICK V.G. KOMBA ${ }^{1 *}$, ROBINSON H. MDEGELA ${ }^{1}$, PETER L.M. MSOFFE ${ }^{1}$ and HANNE INGMER ${ }^{2}$ \\ ${ }^{1}$ Department of Veterinary Medicine and Public Health, Faculty of Veterinary Medicine, Sokoine University of \\ Agriculture, P.O. Box 3021, Morogoro, Tanzania \\ ${ }^{2}$ Department of Veterinary Disease Biology, Faculty of Life sciences, University of Copenhagen, Frederiksberg C, DK- \\ 1870, Denmark
}

\begin{abstract}
The thermotolerant species of Campylobacter have become very important in public health, particularly as agents of infectious diarrhoea in human beings. Though the mechanism by which they cause disease is yet to be fully explained, they have been recognized as the leading cause of bacterial enteritis in both developed and developing countries. The organisms colonize different animal species without causing any symptoms of disease; and humans acquire infections through contact with or consumption of contaminated meat especially raw/undercooked poultry meat. The growing trend of antibiotic resistant Campylobacter isolates continues to pose significant public health challenges. In this review we present the available information generated in Tanzania about Campylobacter infections in humans and animals. We conducted a structured literature search of PUBMED and ScienceDirect electronic databases and identified 15 articles. Studies on humans reported Campylobacter infections in both symptomatic and asymptomatic subjects; with higher prevalence in children under the age of five years. Studies on animals found colonization of both domestic and wild species. Among isolates, some demonstrated antimicrobial resistance. The available information for both human and animal Campylobacteriosis in the country is sparse. It however provides an insight of the bacteriological and epidemiological aspects of Campylobacter infections in the country and eventually creates more awareness on the need to develop control strategies. Since the organism is zoonotic its control strategies should adopt the "One Health" approach involving collaborative efforts from veterinary and human medicine.
\end{abstract}

Keywords: Campylobacter, infections, diarrhoea, epidemiology, humans, animals, Tanzania

\section{Introduction}

Increasing meat consumption around the world goes together with increased concerns and challenges to meat hygiene and safety (Sofos \& Geornaras, 2010). One of the major safety concerns is contamination by Campylobacter, a leading bacterial cause of diarrhoea in humans worldwide, of meat products particularly poultry. Campylobacter species reside in the gut of domesticated warmblooded animals and birds as part of the intestinal microbiota (Ketley, 1997). Of particular importance to humans is their colonization of animals used in food production, including poultry, cattle, sheep and swine (Blaser, 1997; Moore et al., 2005). The most frequently isolated species, Campylobacter jejuni, is now recognized as the leading bacterial cause of food-borne disease in both developed and developing countries (Guerrant et al., 1990; Skirrow, 1990; Butzler, 2004). In addition, infection with $C$. jejuni is the most frequent cause of a form of neuromuscular paralysis known as Guillain-Barré syndrome (Parkhill et al., 2000).

The development of health programmes aimed at controlling diseases, including campylobacteriosis, requires adequate information on the disease including its epidemiology. The absence of national surveillance programmes for Campylobacter infections, particularly in developing countries, makes it difficult to give an accurate picture of the true incidence for some populations (Senok \& Botta, 2009). Thus, resulting into substantial gaps in knowledge about the epidemiology of campylobacteriosis in developing countries. Here we summarize available studies on epidemiological and bacteriological aspects of campylobacteriosis in humans and animals in Tanzania. We further

\footnotetext{
* Correspondence: Erick V.G. Komba; E-mail: ekomba@suanet.ac.tz
} 
identify some challenges that need to be addressed by researchers in the country as far as studies on Campylobacter organisms are concerned.

\section{Methods}

We developed a search algorithm to obtain papers which described Campylobacter infections in Tanzania. More specifically the used algorithm to search the literature had the following key words: "Campylobacter" and "Tanzania" and (humans or children or diarrhoea or animals or goats or cattle or chickens or poultry or pigs or meat or wild animals or environment). The database PubMed provided by the United States National Library of Medicine and ScienceDirect provided by Elsevier, were used. A search through reference lists of initially obtained articles provided some additional research documents on Campylobacter not listed in the PubMed and ScienceDirect databases. A total of 15 papers, published between 1993 to the time of the searches (July, 2011), were obtained and summarized in the present review. During the review of published literature, the data extracted included types and sources of samples, isolation and identification methods, isolation rates and antimicrobial susceptibility profiles (one paper).

\section{Types and sources of samples}

Faecal samples have been identified as the specimens of choice for the isolation of Campylobacter species in patients presenting with gastrointestinal symptoms (Senok \& Botta, 2009). In reported studies on Campylobacter in humans, these samples were collected from patients complaining of enteric problems (symptomatic) seeking for medical services in health facilities within the study areas. Studies on Campylobacter infections in children (Lindblom et al., 1995; Kingamkono et al., 1999) also involved collection of faecal samples from asymptomatic human subjects. Studies on detection of Campylobacter in animals involved collection of faecal samples from both domestic (goats, cattle, ducks, chickens and pigs) and wild (crows, mice and chimpanzees) species. From avians the samples were obtained either through cloacal swabs (live birds), collection of droppings in poultry houses or obtaining caecal contents from intestines of killed birds. Investigations on contamination levels of meat products (Nonga et al., 2009, 2011) involved collection of swabs. Sample collection in all the studies considered the fastidious nature of the microorganism, and so ensured favourable transport and storage conditions including use of transport and enrichment media in the pre-analytical phase.

\section{Isolation/detection of Campylobacter}

For detecting Campylobacter species from different samples, several official protocols are available. However, most medical microbiology laboratories use conventional diagnostic procedures, such as culture and microscopy, for routine detection of enteric pathogens. These procedures include enrichment steps, use of selective culture media, biochemical identification, serotyping, and resistance profiling (Corry et al., 2003; de Boer et al., 2010). Such analyses have been the gold standard for many bacterial pathogens as they have allowed characterization at species and subspecies levels (Persson et al., 2011). Conventional diagnostic methods for Campylobacter require that suspected stool specimens are cultured on selective agar at $42{ }^{\circ} \mathrm{C}$ under microaerophilic conditions for up to 72 hours before a negative report is issued.

Molecular methods provide a means for sensitive and rapid detection of enteric pathogens. However, their broad applications remain limited due to their assumed high costs, inhibition caused by faecal constituents (Monteiro et al., 1997), and the need for specialized laboratories. The 
investigations reported by the publications summarized in this review employed mainly culture methods, particularly the qualitative (enrichment) method and direct plating method. A single study (Kaur et al., 2011) employed molecular biological method in combination with enrichment culture. The enrichment media employed in most of the studies were mainly Bolton broth, Campylobacter enrichment broth (CEB) and Preston broth. The isolation medium employed in most of the studies was mainly charcoal cefaperazone deoxycholate agar (CCDA) plates. Antibiotic free blood agar (in combination with filtration) was also used in some investigations (Kaur et al., 2011; Jacob et al., 2011). A study by Jacob et al. (2011) revealed that the Cape Town protocol (combining filtration and culture on antibiotic-free blood agar) resulted into significantly higher prevalence than the Skirrow's protocol (culture on antibiotic containing agar). The superiority of the Cape Town protocol over the Skirrow's protocol has been documented previously in South Africa (Lastovica et al., 2002). The authors pointed out that the protocol increases isolation of both the number of strains and the number of Campylobacter spp. and species of the related genera Arcobacter and Helicobacter from stool samples.

\section{Identification and typing of Campylobacter}

Phenotypic methods were adopted in identifying the Campylobacter isolates in the reviewed studies. Campylobacter species were mainly identified based on growth temperature preferences, growth in microaerophilic environment, colonial morphology, Gram staining and biochemical characterization of urease, catalase, and oxidase production, as well as sensitivity to nalidixic acid and cephalothin. The studies adopted hippurate hydrolysis test to distinguish between C. jejuni and other species. According to some researchers, however, proper phenotypic identification of Campylobacter isolates, especially differentiation between $C$. jejuni and C. coli based on the hippurate test, might be difficult and could result in false isolate identification (Rönner \& Lindmark, 2007; Nakari et al., 2008). One of the cited studies in this review found that only $74.1 \%$ of 243 isolates identified by phenotypic tests to be $C$. jejuni were confirmed by Polymerase Chain Reaction (PCR) (Mdegela et al., 2006).

The typing of Campylobacter isolates adopted serotyping method (Lindblom et al., 1995) and DNA based molecular techniques (Mdegela et al., 2006; Chuma, 2008; Kaur et al., 2011).

\section{Antimicrobial resistance testing}

Of the reviewed articles only one study on Campylobacter colonization in ducks by Nonga \& Muhairwa (2009) addressed the issue of antimicrobial susceptibility of the Campylobacter isolates. Resistance profiles of the isolates to different antimicrobials were determined by the disk diffusion method (Bauer \& others 1966) on Mueller-Hinton agar. The authors tested the isolates against the

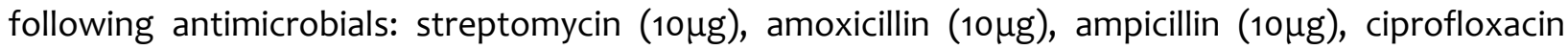
$(5 \mu \mathrm{g})$, cefuroxime sodium $(30 \mu \mathrm{g})$, gentamicin $(10 \mu \mathrm{g})$, cloxacillin $(5 \mu \mathrm{g})$, tetracycline $(30 \mu \mathrm{g})$,

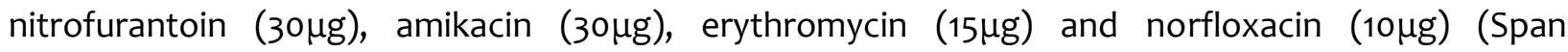
Diagnostic, Surat India). The bacterial growth inhibition zone was measured to assess resistance of the isolates using guidelines stipulated by the National Committee for Clinical Laboratory Standards (NCCLS, 2002).

\section{Campylobacter infections in humans}

Campylobacter species are carried in the intestinal tracts of mammals and birds. Sources of human infections include raw milk, contaminated water, direct contact with pets, and foods, particularly poultry (Pepe et al., 2009). Campylobacter jejuni and C. coli are the species that account for the 
majority of human infections. To date a total of eight studies have been conducted to investigate on Campylobacter infections in humans in Tanzania. Prevalence ranging between o (Gasco'n et al., 2000; Vargas et al., 2004) and 21.6\% (Jacob et al., 2011) have been reported (Table 1).

Table 1: Overall and species specific prevalence of Campylobacter in different studies on humans in Tanzania

\begin{tabular}{|c|c|c|c|c|c|c|}
\hline \multirow{2}{*}{$\begin{array}{l}\text { Age } \\
\text { group }\end{array}$} & \multirow{2}{*}{$\begin{array}{l}\text { Disease status (sample } \\
\text { size) }\end{array}$} & \multirow{2}{*}{$\begin{array}{l}\text { Prev } \\
(\%)\end{array}$} & \multicolumn{3}{|c|}{ Species prevalence (\%) } & \multirow[t]{2}{*}{ References } \\
\hline & & & C. jejuni & C. coli & others & \\
\hline \multirow[t]{2}{*}{$U-5$} & Symptomatic (394) & 18 & 80 & 20 & & Lindblom et al., \\
\hline & Asymptomatic (278) & 12 & 94 & 6 & 0 & 1995 \\
\hline \multirow[t]{2}{*}{ Adults } & Symptomatic (82) & 1 & - & - & - & \\
\hline & Asymptomatic (247) & 1 & - & - & - & \\
\hline$U-5$ & Asymptomatic (445) & 9.4 & - & - & - & $\begin{array}{l}\text { Kingamkono et } \\
\text { al., } 1999\end{array}$ \\
\hline \multirow[t]{2}{*}{$U-5$} & Symptomatic (103) & 0 & - & - & - & Gasco'n et al., \\
\hline & Asymptomatic (206) & 0 & - & - & - & 2000 \\
\hline \multirow[t]{2}{*}{$U-5$} & Symptomatic (348) & 2.56 & - & - & - & Vargas et al., 2004 \\
\hline & Symptomatic (103) & 0 & - & - & - & \\
\hline All & Symptomatic (484) & 1.9 & 100 & 0 & 0 & $\begin{array}{l}\text { Kusiluka et al., } \\
2005\end{array}$ \\
\hline All & Symptomatic (632) & $9 \cdot 3$ & 96.6 & 3.4 & 0 & $\begin{array}{l}\text { Mdegela et al., } \\
2006\end{array}$ \\
\hline$U-5$ & Symptomatic (268) & 19 & 78.4 & 19.6 & 2 & Chuma, 2009 \\
\hline All & Symptomatic (176) & 21.6 & 92.1 & 7.9 & 0 & Jacob et al. 2011 \\
\hline
\end{tabular}

Key: U-5=under five years; Prev = Prevalence

Consistently studies have reported higher prevalence in young individuals as compared to adults (Lindblom et al., 1995; Mdegela et al., 2006). It has been mentioned previously that in developing countries campylobacteriosis is a disease of young children (Khalil et al., 1993; Molbak \& Hojlyng, 1988), while in industrialized countries it is a disease affecting mainly adults (Kaijser, 1988). A study involving children under the age of 5 years showed that males had higher prevalence as compared to females (Chuma, 2009). Studies involving symptomatic and asymptomatic human subjects found no significant differences in infection with Campylobacter (Lindblom et al., 1995; Gasco'n et al., 2000). Lindblom et al. (1995) however found a high prevalence of Campylobacter infection in symptomatic children under the age of 18 months as opposed to asymptomatic counterparts. Similarly investigators elsewhere in other developing countries noticed that Campylobacter is as common in faeces from symptomatic children as from asymptomatic ones but they found a difference among those under the age of 18 months (Steele et al., 1988, Ringertz et al., 1980, Haq \& Rahman 1991). The reason for this has been claimed to be that in developing countries repeated infections in young children induce immunity (Blaser et al., 1985).

In most of the studies carried out in the country, C. jejuni was the dominant species isolated and $C$. coli was less frequently isolated, although the ratio of $C$. coli to $C$. jejuni varied considerably among studies. It has also been reported that in industrialized countries infections caused by $C$. jejuni account for a large proportion of cases of human bacterial gastroenteritis (Friedman et al., 2000).

\section{Campylobacter colonization in poultry}

Today, thermophilic Campylobacter remain the most common cause of acute bacterial enteritis in the world (Moore et al., 2005). Ingestion of contaminated chicken or poor food handling practices associated with raw chicken represents the primary route of transmission to humans. Despite all the 
acquired knowledge on Campylobacter organisms, including the publication of the complete genome sequence for $C$. jejuni (Parkhill et al., 2000), the prevalence of human infections remains high and we still have major problems in producing poultry that are free of Campylobacter. The ability of these bacteria to grow at $42^{\circ} \mathrm{C}$ perhaps reflects their adaptation to the gut of some types of birds (Crushell et al., 2004). Broiler chicks become colonized at a very early stage in their lives and prevalence of colonization among poultry flocks can reach up to $100 \%$ in some areas.

From 1993 to 2011, five different studies were conducted to assess the extent of colonization of chickens (Kazwala et al., 1993; Mdegela et al., 2006; Chuma, 2009; Jacob et al., 2011) and ducks (Nonga \& Muhairwa, 2009) with Campylobacter organisms in Tanzania (Table 2). In all the studies, the subjects were found to be positive for Campylobacter; and C. jejuni accounted for the majority of Campylobacter detected followed by $C$. coli. The findings of these few studies indicate a need for increased surveillance and Campylobacter screening including at the slaughter facility and sales levels.

Table 2: Isolation of Campylobacter in different studies on poultry in Tanzania

\begin{tabular}{|c|c|c|c|c|c|c|}
\hline \multirow{2}{*}{$\begin{array}{l}\text { Poultry } \\
\text { species }\end{array}$} & \multirow{2}{*}{$\begin{array}{l}\text { Number } \\
\text { of } \\
\text { samples }\end{array}$} & \multirow{2}{*}{$\begin{array}{l}\text { Prev } \\
\text { (\%) }\end{array}$} & \multicolumn{3}{|c|}{ Species prevalence $(\%)$} & \multirow[t]{2}{*}{ References } \\
\hline & & & C. jejuni & C. coli & others & \\
\hline Chickens & 1338 & 56.35 & 85.2 & 13.8 & 1 & $\begin{array}{l}\text { Kazwala et al., 1993; Mdegela et } \\
\text { al., 2006; Chuma, 2009; Jacob } \\
\text { et al., } 2011\end{array}$ \\
\hline Ducks & 90 & 80 & 81.9 & 18.1 & 0 & Nonga and Muhairwa, 2009 \\
\hline
\end{tabular}

Key: Prev = prevalence

\section{Campylobacter colonization in livestock}

Many different animal species maintain Campylobacter species with no clinical signs. There do not appear to be significantly different colonization levels of Campylobacter in food animals between developed and developing countries (Padungton \& Kaneene, 2003) and the role of commonly found C. jejuni as a primary pathogen in farm animals is uncertain (Padungton \& Kaneene, 2003). C. jejuni can be found in faeces of diarrhoeic and healthy calves and piglets. Although these organisms are not a problem in animal health terms, they are of major importance to veterinary public health professionals (Moore et al., 2005). Of the farm animals sampled in the reviewed studies goats had the lowest prevalence and pigs the highest (table 3). However, in both studies, C. jejuni accounted for the majority of Campylobacter detected in cattle and pigs; while C. coli was the only species detected in goats. In a study in goats by Jiwa et al. (1994a) it was found that only study subjects in households keeping other animals particularly pigs and poultry were positive carrying isolates similar to those found in these other animals. They concluded that goats are not natural hosts for Campylobacter; and that pigs and poultry serve as sources of infection.

Table 3: Species specific prevalence of Campylobacter in different studies on farm animals in Tanzania

\begin{tabular}{|c|c|c|c|c|c|c|}
\hline \multirow{2}{*}{$\begin{array}{l}\text { Animal } \\
\text { species }\end{array}$} & \multirow{2}{*}{$\begin{array}{l}\text { Number } \\
\text { of } \\
\text { samples }\end{array}$} & \multirow{2}{*}{$\begin{array}{l}\text { Prev } \\
(\%)\end{array}$} & \multicolumn{3}{|c|}{ Species prevalence (\%) } & \multirow[t]{2}{*}{ References } \\
\hline & & & C. jejuni & C. coli & Others & \\
\hline Goats & 168 & 1.8 & 0 & 100 & 0 & Jiwa et al., 1994a \\
\hline Cattle & 1049 & 2.67 & 88.9 & 11.1 & 0 & $\begin{array}{l}\text { Kusiluka et al., 2005; Nonga \& } \\
\text { Karimuribo } 2009\end{array}$ \\
\hline Pigs & 66 & 66.7 & 74 & 26 & 0 & Mdegela et al., 2011 \\
\hline
\end{tabular}

Key: Prev = prevalence 


\section{Campylobacter colonization in wild birds and mice}

Campylobacter species colonize a range of hosts, including domestic animals and wild birds. Playing a reservoir role, wild birds have higher chances of contaminating water sources, environment and food; and in turn transmitting the pathogens to humans and poultry (Altekruse et al., 1999; Luechtefeld et al., 1982). Several studies in developed and developing countries have reported occurrence of Campylobacter, particularly C. jejuni, in wild birds including crows (Ito et al., 1989; Adegbola et al., 1990; Waldenstrom et al., 2002; Saleha, 2004; Molina-Lopez et al., 2011). A study by Adegbola et al. (1990) in Nigeria revealed phenotypical and genotypical similarities among C. jejuni isolates from free flying birds and humans. The present review includes a study that isolated thermophilic Campylobacter from crows at a prevalence of $72.8 \%$ (Mdegela et al., 2006). The obtained high prevalence is of epidemiological and public health significance, as it highlights on the possibility that crows are among sources of thermophilic Campylobacter to humans and chickens in Tanzania. It has been suggested that, free flying birds including crows around poultry farms may transmit thermophilic Campylobacter to chickens if they get access to the rearing houses (Genigeorgis et al., 1986; Altekruse et al., 1999).

In a pilot study conducted by Jiwa et al. (1994b) C. jejuni was isolated from 40\% $(n=20)$ of field mice (Mastomis nataliensis) screened. The authors claimed conformity of biotype profiles of the mice isolates with profiles of human isolates obtained in the same study locality.

\section{Campylobacter colonization in non-human (wild) primates}

As humans are coming into closer proximity with wild primates for a variety of reasons, surveillance and reporting of infectious agents in wild primate populations are increasingly important (Kaur et al., 2011). Previously campylobacteriosis, salmonellosis, and shigellosis in free-ranging human-habituated mountain gorillas were reported in Uganda (Nizeyi et al., 2001). In this review one of the studies was conducted to investigate on colonization of human-habituated chimpanzees (Pan troglodytes schweinfurthii) with Campylobacter organisms. The authors (Kaur et al., 2011) isolated Campylobacter organisms from the faeces of about one-third of the sampled study subjects. Following characterization of the organisms by phenotypic, genotypic and phylogenetic analyses, the authors proposed to classify the obtained isolates into a single novel nomenspecies, Campylobacter troglodytis. The authors recommended further studies to determine whether the organism is pathogenic to chimpanzees and whether this novel Campylobacter colonizes humans and causes enteric disease.

\section{Contamination of meat products with Campylobacter}

Poor slaughter methods and unhygienic meat handling may constitute a potential risk of infections to humans (Steinhauserova et al., 2005). As Campylobacter are enteric organisms and stay in the intestinal contents, cross-contamination of meat can originate from the faeces of the same animal or different animals through the slaughterhouse environment or equipment especially during flaying, evisceration or from cross contamination from hide to carcass (Gannon, 1999; Hakkinen et al., 2007). However, if contaminated water is used to wash carcasses may also be a source of contamination. The present review identified two studies which assessed contamination levels of animal meat products, particularly beef (Nonga et al., 2009) and pork (Nonga et al., 2011).

A survey on cattle carcasses revealed a contamination level of $9.3 \%$. This was fairly high as compared to a carcass contamination level of $2 \%$ previously reported in a neighbouring country of 
Kenya (Osano \& Arimi, 1999). Many more studies elsewhere have reported variable levels of cattle carcasses contamination with Campylobacter organisms (Ono \& Yamamoto 1999; Beach et al., 2002; Hakkinen et al. 2007; Valnegri et al., 2008). On the other hand a study conducted on pork revealed Campylobacter carcass contamination level of $10.6 \%$ which was comparable to findings obtained elsewhere (Aquino et al., 2002). The rate was however fairly low when compared to studies conducted by Steinhauserova et al. (2005) and Malakauskas et al. (2006) who reported higher pig carcass contamination levels ranging from 34-63.6\%. In contrast, studies in developed countries including Poland (Kwiatek et al., 1990), Belgium (Ghafir et al., 2007), and Sweden (Lindblad et al., 2007) reported low carcass contamination levels. Differences in levels of Campylobacter isolation from carcasses may be influenced by the levels of colonization of slaughter animals, abattoir hygiene, slaughter and dressing methods, sampling and analysis methods and sampling plan. The findings of both studies on contamination levels of animal products suggest a need for increased surveillance and Campylobacter screening in food of animal origin so as to better protect consumers.

\section{Seasonal patterns of Campylobacter infections}

In several the United Kingdom, Nordic countries and New Zealand, seasonal peaks in human Campylobacter infections have been observed (Hudson et al., 1999; Nylen et al., 2002). Several other studies have investigated the seasonality of Campylobacter colonization in poultry (Bang et al., 2003; Wilson, 2002; Evans et al., 2002), and attempted to correlate data on human and chicken isolates (Evans et al., 2002). In this review, two studies conducted in Tanzania tried to investigate on seasonal variation on human infections with Campylobacter organisms (Lindblom et al., 1995; Vargas et al., 2004), but didn't find any significant difference. On the other hand studies on Campylobacter colonization in animals were conducted in different seasons and yet produced more or less similar results. Previously a study in the Democratic Republic of Congo, had reported high prevalence of Campylobacter during the wet season (Blasser \& Barth, 1981).

\section{Resistance of Campylobacter isolates to antimicrobials}

While most cases of Campylobacter enteritis are self-limiting, in situations where antibiotic therapy is indicated either erythromycin or ciprofloxacin are the drugs of choice (Tadesse et al., 2011). However data indicate an upward trend of Campylobacter resistance to antibiotics with varying patterns being seen in different countries and regions (Moore et al., 2005; Sack et al., 2001). Campylobacter with resistance to antimicrobial agents have been reported in both developed and developing countries (Ruiz et al., 1998; Saenz et al., 2000; Gaudreau \& Gilbert, 2003; Avrain et al., 2004; Chu et al., 2004; Jain et al., 2005; Moore et al., 2005; Senok et al., 2007; Mazi et al., 2008), and the situation seems to deteriorate more rapidly in developing countries, where there is widespread and uncontrolled use of antibiotics. Studies suggested an association between antimicrobial use in food animals and the development of resistance in human isolates (Padungton \& Kaneene, 2003).

In this review, only a single study on ducks addressed the issue of antimicrobial resistance of the Campylobacter isolates (Nonga \& Muhairwa, 2009), in which fifty isolates of C. jejuni, the best characterized and most clinically relevant species in this genus, were tested for sensitivity to twelve antimicrobials. The authors reported that all the tested isolates were susceptible to streptomycin, nitrofurantoin and amikacin; and at least half of them were resistant to cefuroxime sodium, tetracycline and ampicillin. They further indicated that between $20-50 \%$ of isolates were resistant to erythromycin, gentamicin, cloxacillin and amoxicillin; and $10 \%$ and $16 \%$ of the $C$. jejuni were resistant to norfloxacin and ciprofloxacin respectively. The study observed that isolates from adult ducks showed significantly higher levels of resistance to most antibiotics than did duckling isolates. 
Previous reports indicate that $C$. jejuni has been found to be sensitive to several classes of antibiotics, including macrolides (especially erythromycin), which have been traditionally utilized as first-line therapy, and quinolones such as ciprofloxacin (Moore et al., 2005). However, high levels of quinolone resistance in Campylobacter have been documented in Europe and Asia (Ruiz et al., 1998; Saenz et al., 2000; Chu et al., 2004; Jain et al., 2005). Campylobacter resistance to this group of antibiotics is currently deemed a rapidly emerging global problem; and the widespread use of fluoroquinolones in clinical practice and utilization in veterinary practice are thought to be contributing factors for these high levels of resistance. Increasing levels of Campylobacter resistance to tetracycline have also been reported (Mazi et al., 2008; Senok et al., 2007; Gaudreau \& Gilbert, 2003), some studies attributing the pattern to its persistent use in animal husbandry. A described natural horizontal transfer of tetracycline resistance gene (tet $(\mathrm{O})$ gene) without antimicrobial selection pressure between $\mathrm{C}$. jejuni in the digestive tract of chickens (Avrain et al., 2004) may also explain these high rates of tetracycline resistance.

\section{Conclusion}

In the present review summarized reports provide evidence of Campylobacter infections both in humans and animals (including the wild), as well as contamination of meat products in Tanzania. One of the reports also informs of the existence of antibiotic resistant Campylobacter isolates in the country. This has an implication on public health as the organism is zoonotic. We recommend collaborative efforts from veterinary and human medicine, as promoted by the "one health" approach, to allow for efficient and more effective strategies for prevention and control of infections both in human and animal populations. One of the challenges for researchers in the country would be to conduct further work using DNA based techniques for determination of relatedness of the isolates circulating in animals and humans. There is also much to be done in the country in order to understand the pattern and trends of antibiotic resistance in both human and animal derived Campylobacter isolates. Furthermore, environmental reservoirs of Campylobacter and risk factors for human infections with Campylobacter need to be investigated.

\section{Acknowledgements}

This study received financial support from Danish International Development Agency through Livestock Enterprises Project.

\section{References}

Adegbola, R.A., Alabi, S.A., Akinkuade, F.O., Coker, A.O. \& Odugbemi, T. (1990) Correlation between human and animal bioserogroups of Campylobacter isolates in Nigeria. Journal of Tropical Medicine and Hygiene 93, 280-283.

Altekruse, S.F., Stern, N.J., Fields, P.I. \& Swerdlow, D.L. (1999) Campylobacter jejuni an emerging food-borne pathogen. Emerging Infectious Disease 5, 28-35.

Aquino, M.H., Pacheco, A.P., Ferreira, M.C. \& Tibana, A. (2002) Frequency of isolation and identification of thermophilic Campylobacter from animals in Brazil. Veterinary Journal 164, 159-161.

Avrain, L., Vernozy-Rozand, C. \& Kempf, I. (2004) Evidence for natural horizontal transfer of tetO gene between Campylobacter jejuni strains in chickens. Journal of Applied Microbiology 97, 134-140. 
Bang, D.D., Nielsen, E.M., Knudsen, K., Madsen, M. (2003) A one year study of campylobacter carriage by individual Danish broiler chickens as the basis for selection of Campylobacter species strains for a chicken infection model. Epidemiology \& Infection 130: 320-323.

Bauer, A.W., Kirby, W.M., Sherris, J.C. \& Turck, M. (1966) Antibiotic susceptibility testing by a standardized single disk method. Technical Bulletin of the Registry of Medical Technologists 36, 49-52.

Beach, J.C., Murano, E.A. \& Acuff, G.R., (2002) Prevalence of Salmonella and Campylobacter in beef cattle from transport to slaughter. Journal of Food Protection 65, 1687- 1693.

Blaser, M.J. \& Reller, L.B. (1981) Campylobacter enteritis. New England Journal of Medicine 305, 14441452.

Blaser, M.J., Black, R.E., Duncan, D.J. \& Amer, J. (1985) Campylobacter jejuni-specific antibodies are elevated in healthy Bangladeshi children. Journal of Clinical Microbiology 21, 164-167.

Butzler, J.P. (2004) Campylobacter, from obscurity to celebrity. Clinical Microbiology and Infection 10, 868-876.

Chu, Y.W., Chu, M.Y., Luey, K.Y., Ngan, Y.W., Tsang, K.L. \& Kam, K.M. (2004) Genetic relatedness and quinolone resistance of Campylobacter jejuni strains isolated in 2002 in Hong Kong. Journal of Clinical Microbiology 42, 3321-3323.

Chuma, I.S. (2009) Prevalence, risk factors and genetic relatedness among thermophilic Campylobacter from humans and chickens using RAPD-PCR in Morogoro, Tanzania. A thesis submitted for the award of a Master of Veterinary Medicine at Sokoine University of Agriculture, Morogoro, Tanzania. 112pp.

Crushell, E., Harty, S., Sharif, F. \& Bourke, B. (2004) Enteric campylobacter: purging its secrets? Pediatric Research 55, 3-12.

de Boer, R.F., Ott, A., Kesztyus, B. \& Kooistra-Smid A.M.D. (2010) Improved detection of five major gastrointestinal pathogens by use of a molecular screening approach. Journal of Clinical Microbiology 48, 4140-4146.

Evans, M.C., Christiansen, L.E., Wedderkop, A., Gerner- Smidt, P., Wegener, H.C. (2002) Effects of climate on Campylobacter species in humans and broilers in Denmark. In: Abstracts of the 3 rd International Conference on Emerging Infectious Diseases. Atlanta: 20-24 March 2002. Atlanta, Georgia: Centers for Disease Control and Prevention.

Friedman, C.R., Neimann, H., Wegener, H.C. \& Tauxe, R.V. (2000) Epidemiology of Campylobacter jejuni in the United States and other industrialized nations. In: I. Nachamkin \& M.J. Blaser (eds). Campylobacter. Washington: ASM Press. pp 121-138.

Gannon, V.P.J. (1999) Control of Escherichia coli O157 at slaughter. In Escherichia coli O157 in Farm Animals. C.S. Stewart \& H.J. Flint (eds), pp 169-193. Wallingford: CAB International.

Gaudreau, C. \& Gilbert, H. (2003) Antimicrobial resistance of Campylobacter jejuni subsp. jejuni strains isolated from humans in 1998 to 2001 in Montreal, Canada. Antimicrobial Agents Chemotherapy 47, 2027-2029.

Gasco'n, J., Vargas, M., Schellenberg, D., Urassa, H., Casals, C., Kahigwa, E., Aponte, J.J., Mshinda, H. \& Vila, J. (2000) Diarrhea in Children under 5 Years of Age from Ifakara, Tanzania: a CaseControl Study. Journal of Clinical Microbiology 38, 4459-4462.

Genigeorgis, C., Hassuneh M. \& Collins, P. (1986) Campylobacter jejuni infection on poultry farms and its effect on poultry meat contamination during slaughter. Journal of Food Protection 49, 895903.

Ghafir, Y., China, B., Dierick, K., De Zutter, L. \& Daube, G. (2007) A seven-year survey of Campylobacter contamination in meat at different production stages in Belgium. International Journal of Food Microbiology 116, 111-120. 
Guerrant, R.L., Hughes, J.M., Lima, N.L. \& Crane, J. (1990) Diarrhea in developed and developing countries: magnitude, special settings, and etiologies. Review of Infectious Diseases 12 (Suppl 1), S41-50.

Hakkinen, M., Heiska, H, \& Marja-Liisa, H. (2007) Prevalence of Campylobacter species in cattle in Finland and antimicrobial susceptibilities of bovine Campylobacter jejuni strains. Applied and Environmental Microbiology 73, 3232-3238.

Haq, J.A. \& Rahman, K.M. (1991) Camplylobacter jejuni as a cause of acute diarrhoea in children: a study at an urban hospital in Bangladesh. Journal of Tropical Medicine and Hygiene 94, 50-54.

Hudson, J.A., Nicol, C., Wright, J., Whyte, R., Hasell, S.K. (1999) Seasonal variation of Campylobacter types from human cases, veterinary cases, raw chicken, milk and water. Journal of Applied Microbiology 87, 115-124.

Ito, K., Kubokura, Y., Kaneko, K., Totake, Y. \& Ogawa, M. (1989) Occurrence of Campylobacter jejuni in free-living wild birds from Japan. J. Wildl. Dis. 24, 467-470.

Jacob, P., Mdegela, R. H. \& Nonga H. E. (2011). Comparison of Cape Town and Skirrow's Campylobacter isolation protocols in humans and broilers in Morogoro, Tanzania. Tropica Animal Health Production. doi: 10.1007/s11250-011-9799-z

Jain, D., Sinha, S., Prasad, K.N. \& Pandey, C.M. (2005) Campylobacter species and drug resistance in a north Indian rural community. Transactions of the Royal Society of Tropical Medicine and Hygiene 99, 207-214.

Jiwa, S.F.H., Kazwala, R.R. \& Namahungu, E. (1994a) Prevalence of Campylobacter spp. in clinically normal goats kept under various management systems in urban Tanzania. Small Ruminant Research 15, 97-100.

Jiwa, S.F.H., Phiri, E.C.J.H. \& Kimera, S.I. (1994b). Isolation of thermophilic Campylobacter from clinically normal calves, goats, field mice and purging children at Sokoine University of Agriculture (SUA) campus, Morogoro, Tanzania. Tanzania Veterinary Journal 14(3-4), 103-109.

Kaijser, B. (1988) Campylobacter jejuni/coli. APMIS 96, 283-288.

Kaur, T., Singh, J., Huffman, M.A., Petrželkova, K.J., Taylor, N.S., Xu, S., Dewhirst, F.E., Paster, B.J., Debruyne, L., Vandamme, P. \& Fox, J.G. (2011) Campylobacter troglodytis sp. nov., isolated from feces of human-habituated wild chimpanzees (Pan troglodytes schweinfurthii) in Tanzania. Applied and Environmental Microbiology 77, 2366-2373.

Kazwala, R.R., Jiwa, S.F.H. \& Nkya, A.E. (1993) The role of management systems in the epidemiology of thermophilic Campylobacters among poultry in Eastern zone of Tanzania. Epidemiology and Infection 110, 273-278.

Ketley, J.M. (1997) Pathogenesis of enteric infection by Campylobacter. Microbiology 143, 5-21.

Khalil, K., Lindblom, G.B., Mazhar, K., Khan, S.R. \& Kaijser, B. (1993) Early child health in Lahore, Pakistan, VIII Microbiology. Acta Paediatrica 390 (Suppl), 87-94.

Kingamkono, R., Sjogren, E. \& Svanberg, U. (1999) Enteropathogenic bacteria in faecal swabs of young childrenfed on lactic acid-fermented cereal gruels. Epidemiology \& Infection 122, 23-32.

Kusiluka, L.J.M., Karimuribo, E.D., Mdegela, R.H., Luoga, E.J., Munishi, P.K.T., Mlozi M.R.S., \& Kambarage, D.M. (2005) Prevalence and impact of water-borne zoonotic pathogens in water, cattle and humans in selected villages in Dodoma Rural and Bagamoyo districts, Tanzania. Physics and Chemistry of the Earth 30, 818-825.

Kwiatek, K., Wolton, B. \& Stern, N.J. (1990) Prevalence and distribution of Campylobacter species on poultry and selected red meat carcasses in Poland. Journal of Food Protection 53, 127-130.

Lindblad, M., Lindmark, H., Lambertz, S. T. \& Lindqvist, R. (2007) Microbiological baseline study of swine carcasses at Swedish slaughterhouses. Journal of Food Protection 70, 1790-1798.

Lindblom, G.B., Ahren, C., Changalucha, J., Gabone, R., Kaijser, B., Nilsson, L.A., Sjogren, E., Svennerholm, A.M., Temu, M. (1995) Campylobacter jejuni/coli and enterotoxigenic 
Escherichia coli (ETEC) in faeces from children and adults in Tanzania. Scandinavian Journal of Infectious Diseases 27, 589-593.

Luechtefeld, N.W., Reller, L.B., Blaser, M.J. \& Wang, W.L.L. (1982) Comparison of atmospheres of incubation for primary isolation of Campylobacter fetus subspecies jejuni from animal species: $5 \%$ oxygen versus candle jar. Journal of Clinical Microbiology 15, 53-57.

Malakauskas, M., Jorgensen, K., Nielsen, E.M., Ojeniyi, B. \& Olsen, J.E. (2006) Isolation of Campylobacter species from a pig slaughterhouse and analysis of cross-contamination. International Journal of Food Microbiology 108, 295-300.

Mazi, W., Senok, A., Al-Mahmeed, A., Arzese, A., Bindayna, K. \& Botta, G. (2008) Trends in antibiotic sensitivity pattern and molecular detection of tet(O)-mediated tetracycline resistance in Campylobacter jejuni isolates from human and poultry sources. Japanese Journal of Infectious Diseases 61, 82-84.

Mdegela, R.H., Laurence, K., Jacob, P. \& Nonga, H.E. (2011) Occurrences of thermophilic Campylobacter in pigs slaughtered at Morogoro slaughter slabs, Tanzania. Tropical Animal Health and Production 43, 83-87.

Mdegela, R.H., Nonga, H.E., Ngowi, H.A. \& Kazwala, R.R. (2006) Prevalence of thermophilic Campylobacter infections in humans, chickens and crows in Morogoro, Tanzania. Journal of Veterinary Medicine B 53, 116-121.

Molbak, K. \& Hojlyng, N. (1988) High prevalence of Campylobacter excretors among Liberian children related to environmental conditions. Epidemiology \& Infection 100, 227-237.

Molina-Lopez, R.A., Valverdú, N., Martin, M., Mateu, E., Obon, E., Cerdà-Cuéllar, M. \& Darwich, L. (2011) Wild raptors as carriers of antimicrobial resistant Salmonella and Campylobacter strains. Veterinary Record 168, 565b.

Monteiro, L., Bonnemaison, D., Vekris, A., Petry, K., Bonnet, J., Vidal, R., Cabrita, J. \& Megraud, F. (1997) Complex polysaccharides as PCR inhibitors in feces: Helicobacter pylori model. Journal of Clinical Microbiology 35, 995-998.

Moore, J.E., Corcoran, D., Dooley, J.S., Fanning, S., Lucey, B., Matsuda, M., McDowell, D.A., Megraud, F., Millar, B.C., O'Mahony, R., O'Riordan, L., O'Rourke, M., Rao, J.R., Rooney, P.J., Sails, A. \& Whyte, P. (2005) Campylobacter. Veterinary Research 36, 351-382.

Nakari, U.M., Puhakka, A. \& Siitonen, A. (2008) Correct identification and discrimination between Campylobacter jejuni and C. coli by a standardized hippurate test and species-specific polymerase chain reaction. European Journal of Clinical Microbiology and Infectious Diseases 27, 513-518.

NCCLS (2002) Performance Standards for Antimicrobial Disk and Dilution Susceptibility Tests for Bacteria Isolated from Animals: Approved Standard. 2nd edn. Document M31- A2. NCCLS.

Nizeyi, J.B., Innocent, R.B., Erume, J., Kalema, G.R.N.N., Cranfield, M.R. \& Graczyk, T.K. (2001) Campylobacteriosis, salmonellosis, and shigellosis in free-ranging human-habituated mountain gorillas of Uganda. Journal of Wildlife Diseases 37, 239-244.

Nonga, H.E. \& Muhairwa, A.P. (2009) Prevalence and antibiotic susceptibility of thermophilic Campylobacter isolates from free range domestic duck (Cairina moschata) in Morogoro municipality, Tanzania. Tropical Animal Health Production 42, 165-172.

Nonga, H.E., Sells, P. \& Karimuribo, E.D. (2009) Occurrences of thermophilic Campylobacter in cattle slaughtered at Morogoro municipal abattoir, Tanzania. Tropical Animal Health \& Production 42, 73-78.

Nylen, G., Dunstan, F., Palmer, S.R., Andersson, Y., Bager, F., Cowden, J., Feierl, G., Galloway, Y., Kapperud, G., Megraud, F., Molbak, K., Petersen, L.R. \& Ruutu, P. (2002) The seasonal distribution of Campylobacter infection in nine European countries and New Zealand. Epidemiology and Infection 128, 383-390. 
Ono, K. \& Yamamoto, K. (1999) Contamination of meat with Campylobacter jejuni in Saitama. International Journal of Food Microbiology 47, 211-219.

Osano, O. \& Arimi, S. (1999) Retail poultry and beef as source of Campylobacter jejuni. East African Medical Journal 76, 141-143.

Padungton, P. \& Kaneene, J. B. (2003) Campylobacter species in human, chickens, pigs and their antimicrobial resistance. Journal of Veterinary Medical Science 65, 161-70.

Parkhill, J., Wren, B.W., Mungall, K., Ketley, J.M., Churcher, C., Basham, D., Chillingworth, T., Davies, R.M., Feltwell, T., Holroyd, S., Jagels, K., Karlyshev, A.V., Moule, S., Pallen, M.J., Penn, C.W., Quail, M.A., Rajandream, M.A., Rutherford, K.M., van Vliet, A.H., Whitehead, S. \& Barrell, B.G. (2000) The genome sequence of the food-borne pathogen Campylobacter jejuni reveals hypervariable sequences. Nature 403, 665-668.

Pepe, T., De Dominicis, R., Esposito, G., Ventrone, I., Fratamico, P.M. \& Cortesi, M.L. (2009) Detection of Campylobacter from poultry carcass skin samples at slaughter in Southern Italy. Journal of Food Protection 72, 1718-1721.

Persson, S., de Boer, R.F., Kooistra-Smid, A.M.D. \& Olsen, K.E.P., (2011) Five commercial DNA extraction systems tested and compared on a stool sample collection. Diagnostic Microbiology and Infectious Disease 69, 240-244.

Ringertz, S., Rockhill, R.C., Ringertz, O. \& Sutomo, A. (1980) Campylobacter fetus subsp. jejuni as a cause of gastroenteritis in Jakarta, Indonesia. Journal of Clinical Microbiology 12, 538-540.

Rönner, A.C. \& Lindmark, H. (2007) Quantitative detection of Campylobacter jejuni on fresh chicken carcasses by realtime PCR. Journal of Food Protection 70, 1373-1378.

Ruiz, J., Goni, P., Marco, F., Gallardo, F., Mirelis, B., Jimenez De Anta, T. \& Vila, J. (1998) Increased resistance to quinolones in Campylobacter jejuni: a genetic analysis of gyrA gene mutations in quinolone-resistant clinical isolates. Microbial Immunology 42, 223-226.

Sack, D.A., Lyke, C., McLaughlin, C. \& Suwanvanichkij, V. (2001) Review of Campylobacter. In Antimicrobial resistance in Shigellosis, Cholera and Campylobacteriosis. World Health Organization (WHO), Switzerland: 31-50.

Saenz, Y., Zarazaga, M., Lantero, M., Gastanares, M.J., Baquero, F. \& Torres, C. (2000) Antibiotic resistance in Campylobacter strains isolated from animals, foods, and humans in Spain in 1997-1998. Antimicrobial Agents and Chemotherapy 44, 267-271.

Saleha, A.A. (2004) Epidemiological study on the colonization of chickens with Campylobacter in broiler farms in Malaysia: possible risk and management factors. International Journal of Poultry Science 3, 129-134.

Senok, A., Yousif, A., Mazi, W., Sharaf, E., Bindayna, K., Elnima el, A. \& Botta, G. (2007) Pattern of antibiotic susceptibility in Campylobacter jejuni isolates of human and poultry origin. Japanese Journal of Infectious Disease 60, 1-4.

Senok, A.C. \& Botta, G.A. (2009) Campylobacter enteritis in the Arabian Gulf. Journal of Infection in Developing Countries 3, 74-82.

Skirrow, M.B. (1990) Campylobacter. Lancet 336: 921-923.

Sofos, J.N. \& Geornaras, I. (2010) Overview of current meat hygiene and safety risks and summary of recent studies on biofilms, and control of Escherichia coli $0157: \mathrm{H} 7$ in nonintact, and Listeria monocytogenes in ready-to-eat, meat products. Meat Science 86. 2-14.

Steele, A.D., Geyer, A., Alexander, J.J., Crewe-Brown, H.H., Fripp, P.J. (1988) Enteropathogens isolated from children with gastroenteritis at Ga-Rankuwa Hospital, South Africa. Annals of Tropical Paediatrics 8, 262-267.

Steinhauserova, I., Nebola, M. \& Mikulicova, M. (2005) Prevalence of thermophilic Campylobacter species in slaughtered pigs in the Czech Republic, 2001-2003. Veterinary Medicine-Czech 50, 171-174. 
Tadesse, D.A., Bahnson, P.B., Funk, J.A., Thakur, S., Morgan Morrow, W.E., Wittum, T., DeGraves, F., Rajala-Schultz, P. \& Gebreyes, W.A. (2011) Prevalence and Antimicrobial Resistance Profile of Campylobacter spp. isolated from conventional and antimicrobial-free swine production systems from different US Regions. Foodborne Pathogens and Disease 8, 367-374.

Valnegri, L., Franzoni, M., Colombo, F. \& Soncini, G. (2008) Isolation and identification of thermophilic Campylobacter species in cattle carcasses from a northern Italian slaughterhouse. Italian Journal of Food Science 20, 433-438.

Vargas, M., Gasco'n, J., Casals, C., Schellenberg, D., Urassa, H., Kahigwa, E., Ruiz, J., \& Vila, J. (2004) Etiology of diarrhea in children less than five years of age in Ifakara, Tanzania. American Journal of Tropical Medicine and Hygiene 70, 536-539.

Waldenstrom, J., Broman, T., Carlsson, I., Hasselquist, D., Achterberg, R.P., Wagenaar, J.A. \& Olsen, B. (2002) Prevalence of Campylobacter jejuni, Campylobacter lari, and Campylobacter coli in different ecological guilds and taxa of migrating birds. Applied and Environmental Microbiology 68, 5911-5917.

Wilson, I.G. (2002) Salmonella and campylobacter contamination of raw retail chickens from different producers: a six-year survey. Epidemiology \& Infection 129, 635-645. 